\title{
Prevalence of left ventricular 'rigid body rotation', the near absence of left ventricular twist (insights from the MAGYAR studies)
}

\author{
Attila Nemes*, Árpád Kormányos \\ Department of Medicine, Medical Faculty, Albert Szent-Györgyi Clinical Center, University of Szeged, 6725 Szeged, Hungary \\ *Correspondence: nemes@in2nd.szote.u-szeged.hu (Attila Nemes) \\ Academic Editor: Tasneem Z. Naqvi \\ Submitted: 15 September 2021 Revised: 15 November 2021 Accepted: 24 November 2021 Published: 8 January 2022
}

\begin{abstract}
Left ventricular (LV) twist is defined as the wringing motion of the LV around its long-axis during systole generated by rotation of the LV apex in a counterclockwise direction, as viewed from the apex, while the LV base moves in a clockwise direction. In several cases, the LV apex and base move in the same direction during ejection demonstrating a special condition called as LV 'rigid body rotation'. The present review aimed to summarize our knowledge about this rare but not fully understood entity demonstrating its theoretic pathophysiologic background, clinical significance, associated diseases, and reversibility based on available literature.
\end{abstract}

Keywords: Echocardiography; Left ventricular; Rotation; Twist; Speckle-tracking; Two-dimensional; Three-dimensional

\section{The normal twisting motion of the heart}

Left ventricular (LV) twist represents the wringing motion of the heart along its long-axis during systole generated by rotation of the LV apex in a counterclockwise $(\mathrm{CCw})$ direction, as viewed from the apex, while the LV base moves in a clockwise $(\mathrm{Cw})$ direction [1]. One of the main components of the mechanical efficacy of the heart is the peak systolic LV twist, resulting in $60 \% \mathrm{LV}$ ejection fraction (EF) with only $15 \%$ fiber shortening [2]. This wringing motion is generated by the helical arrangement of myocardial fibers, subendocardially, the spiral holds a left-handed helix, while there is a right-handed helix in the subepicardium. The myocyte helix angle changes continuously from the subendocardium to the subepicardium, typically ranging from +60 degree at the subendocardium to -60 degree at the subepicardium [3]. The mid-myocardial circumferential fibers shorten simultaneously with the oblique fibers in the right- and left-handed helices during ejection providing a horizontal counterforce throughout ejection. The subepicardial fibers control the direction of the peak systolic LV twist, mainly due to their longer arm of movement. Therefore, the absence of the endocardial helix would result in increased $\mathrm{Cw}$ basal and $\mathrm{CCw}$ apical rotation, while the absence of the epicardial helix would cause $\mathrm{CCw}$ basal and $\mathrm{Cw}$ apical LV rotation [4].

\section{Estimation of $L V$ rotational mechanics}

In earlier years, LV rotational mechanics could be examined only by invasive (microsonometry) or expensive (magnetic resonance imaging) methodologies [1]. Two-dimensional (2D) speckle-tracking echocardiography (STE) is a non-invasive opportunity to assess LV rotational mechanics. However, the LV is a three-dimensional (3D) chamber, therefore its examination in 2D theoretically is associated with loss of information. This fact leads to guidelines not supporting 2DSTE in the quantification of LV rotational mechanics [5]. Moreover, significant differences between 2DSTE- and 3DSTE-derived LV rotational parameters could also be demonstrated [6]. 3DSTE is a novel method for 3D assessment of LV. Shortly, full volume 'echocloud' (3D echocardiographic dataset) is acquired using 3D capable matrix transducer at the beginning of 3DSTE examination in which analysis could be performed online or offline using a special software by creating a virtual 3D model of the LV. Volumetric changes in LV respecting the cardiac cycle, LV contractility represented by LV strains and LV rotational parameters could be calculated at the same time using this cast [7] (Fig. 1).

\section{MAGYAR studies}

The aim of our study conducted in our tertiary cardiovascular center was to assess the diagnostic and potentially prognostic values of 3DSTE-derived parameters including LV rotational parameters. LV apical and basal rotations and LV twist were measured in healthy subjects (MAGYAR-Healthy Study) and in several pathological states (MAGYAR-Path Study). LV rotational parameters were measured in elite athletes (MAGYAR-Sport Study), in twins (MAGYAR-Twin Study), in foetuses (MAGYARFetus Study) and during stress protocols (MAGYAR-Stress Study) [7]. ('Magyar' means 'Hungarian' in Hungarian language).

\section{Near absence of $L V$ twist $-L V$ 'rigid body rotation'}

In special circumstances, LV 'rigid body rotation' (RBR), the near absence of LV twist may develop due to 


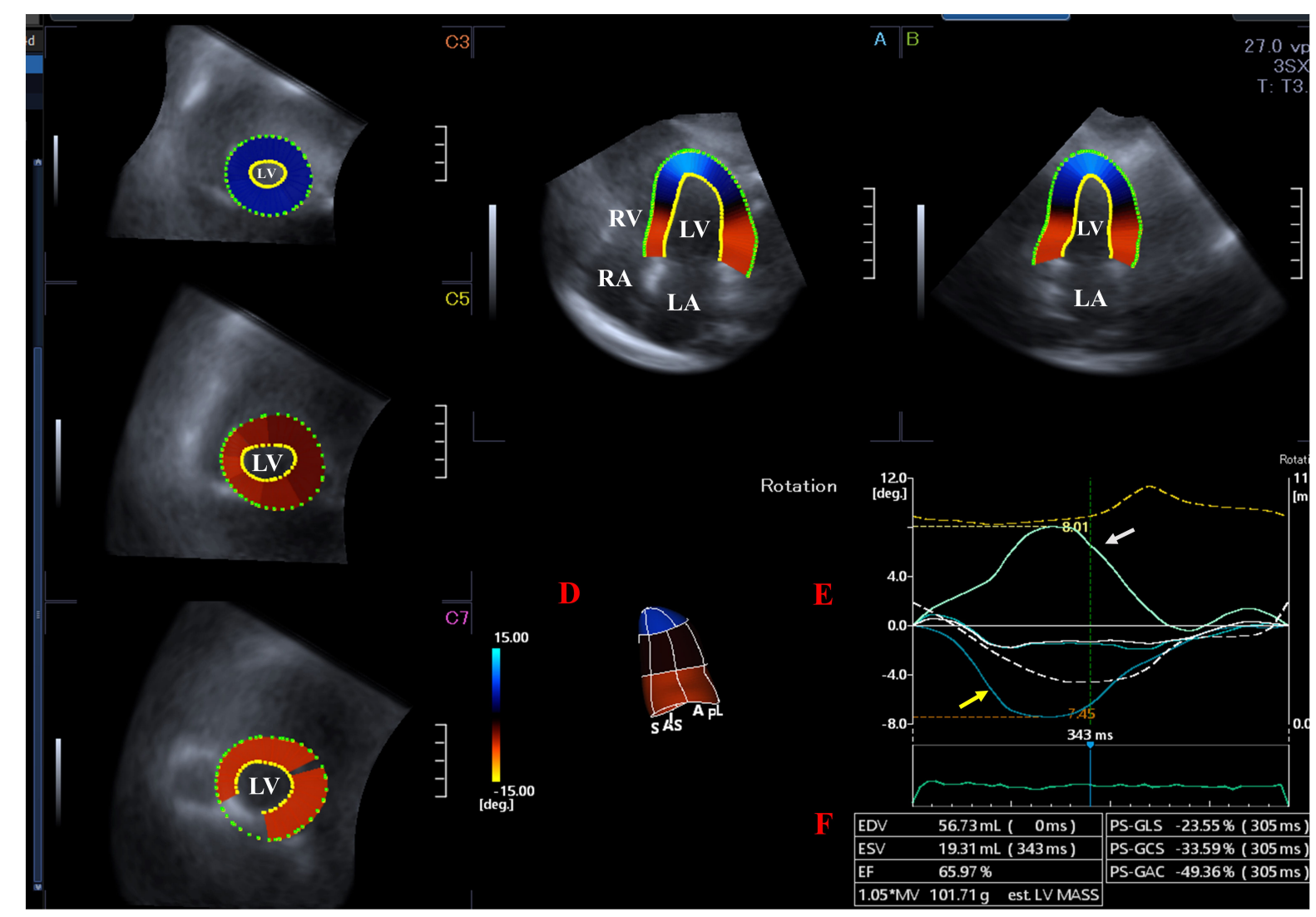

Fig. 1. Left ventricular (LV) rotational mechanics assessed by three-dimensional (3D) speckle-tracking echocardiography. Apical four-chamber (A) and two-chamber views (B) and basal (C3), midventricular (C5) and apical (C7) short-axis views are presented extracted from the acquired 3D volumetric dataset. LV cast (D), curves representing apical (white arrow) and basal (yellow arrow) LV rotations (E) and LV volumetric parameters (F) generated by the software are presented. LA, left atrium; LV, left ventricular; RA, right atrium; RV, right ventricle; EDV, end-diastolic volume; ESV, end-systolic volume; EF, ejection fraction; GLS, LV global longitudinal strain; GCS, LV global circumferential strain; GAC, LV global area strain (change).

changes in the direction of the movement of the myocardial fibers, the LV apex and LV base move in the same clockwise $(\mathrm{Cw})$ or counterclockwise $(\mathrm{CCw})$ direction [8] (Figs. 2,3). This phenomenon is considered to be normal in healthy neonates with an immature heart, LV-RBR has occurred due to the counterclockwise rotation of the basal and apical fibers [9]. However, later the normal LV rotational mechanics develops. In some special clinical circumstances, LV-RBR persists in adults, its real clinical significance and prevalence are not known. The present review aimed to summarize related information from known literature mainly based on the results of the MAGYAR Studies.

\section{Cardiac diseases associated with LV-RBR}

\subsection{Noncompaction cardiomyopathy}

LV noncompaction cardiomyopathy (NCCM) or spongiform cardiomyopathy is a rare congenital cardiomyopathy due to an intra-uterine arrest of compaction of the myocardial fibres during embryogenesis [10]. NCCM is characterized by a thin, compacted epicardium and a thick non-compacted endocardium, with prominent trabeculation and deep intertrabecular recesses [10,11]. Characteristic complications of NCCM include chronic heart failure, lifethreatening ventricular arrhythmias and systemic embolic events $[10,11]$.

According to the literature, NCCM is the most extensively examined LV-RBR-related disease, where its prevalence ranged from $26 \%$ to $100 \%$ (Table 1) [11-21]. van Dalen et al. [12] assessed patients with dilated cardiomyopathy (DCM), healthy subjects and cases with prominent trabeculations, of whom expert opinion in NCCM defined some of them having NCCM, and found that LV-RBR was an objective, quantitative and reproducible functional criterion, and had a good predictive value in the diagnosis of NCCM. Specificity and sensitivity of LV-RBR was $88 \%$ and $78 \%$ in differentiating NCCM from LV "hypertrabeculation", respectively [12]. Cw LV-RBR was detected in most NCCM cases $[11,12,15,18-20]$, which was found to be related to LV-EF [17]. Almost one-third of the relatives of NCCM patients showed LV-RBR, the ratio of $\mathrm{Cw}$ and 


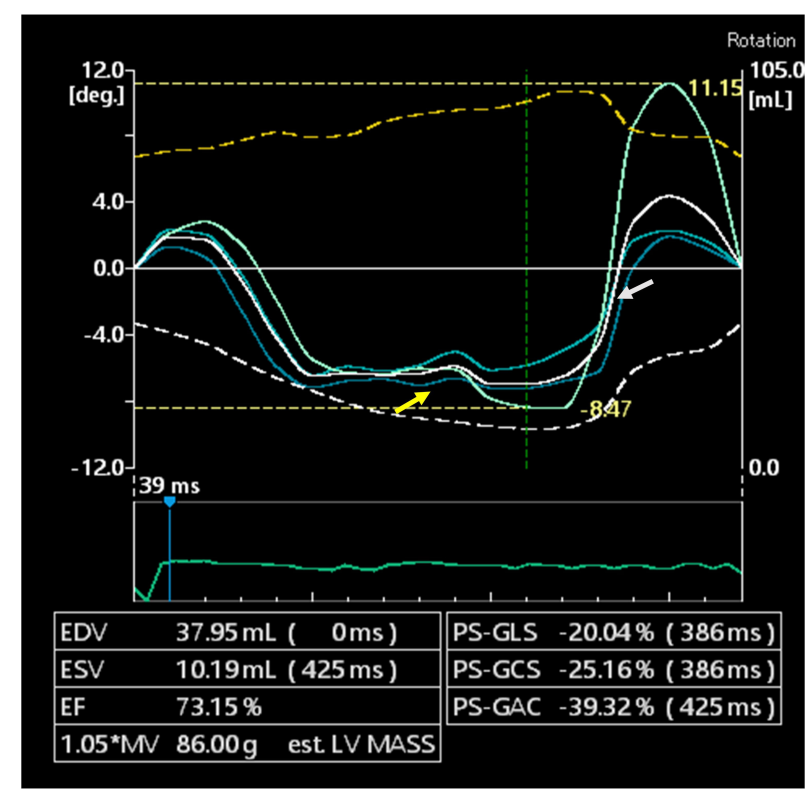

Fig. 2. Abnormal clockwise apical (white arrow) and normal clockwise basal (yellow arrow) left ventricular rotations (clockwise left ventricular 'rigid body rotation'). LV, left ventricular; EDV, end-diastolic volume; ESV, end-systolic volume; EF, ejection fraction; LV-GLS, LV global longitudinal strain; LVGCS, LV global circumferential strain; LV-GAC, LV global area strain (change).

$\mathrm{CCw}$ direction was the same [18]. Ratio of LV-RBR was significantly different between NCCM children and subjects with hypertrabecularization [19]. In another study, reverse LV apical rotation (Cw LV-RBR) was present in 39\% of NCCM children [20].

\subsection{Dilated or nonischaemic cardiomyopathy}

LV rotational mechanics was examined only in a limited number of studies in series of DCM or nonischaemic (NICM) cardiomyopathy patients. $88-100 \%$ of patients showed Cw LV-RBR [22,23]. Reversed apical rotation (Cw LV-RBR) and loss of LV torsion was found to be associated with significant LV remodelling, increased electrical dyssynchrony, reduced systolic function, and increased filling pressures in patients with DCM, indicating a more advanced stage of the disease [22]. The normal torsion pattern was observed more frequently in NICM patients without mid-wall fibrosis (MWF), and LV-RBR was more frequently observed in patients with MWF [24].

\subsection{Hypertensive and other special cardiomyopathies}

Hypertensive heart disease includes a number of complications due to high blood pressure including LV hypertrophy, heart failure, etc. In hypertensive cardiomyopathy patients with reduced LV-EF, $32 \%$ of subjects showed predominantly $\mathrm{Cw}$ LV-RBR suggesting compromised LV apical rotation similarly to NCCM/DCM/NICM patients [25].
Theoretically hypertension-related abnormalities, fibrosis, etc. could explain these findings. CCw LV-RBR was found in cases with peripartum and chloroquine cardiomyopathies $[26,27]$. In a small study with hypertrophic cardiomyopathy (HCM), only 1 case out of 18 showed Cw LV-RBR [21].

\subsection{Infiltrative cardiac disorders}

Regarding the literature, only positron emission tomography-proven cardiac lymphoma [28] and biopsyproven cardiac amyloidosis (CA) [29] were found to be related to $\mathrm{LV}-\mathrm{RBR}$ at this moment. Interestingly, $\mathrm{CCw} \mathrm{LV}$ RBR could be demonstrated in all cases suggesting compromised LV basal rotation [28,29]. Infiltration of the myocardial tissue by amyloid or lymphomatous tissue could lead to changes in LV twisting deformation [28,29].

\subsection{Congenital heart diseases}

LV-RBR was reported only in a few case reports in certain congenital heart diseases (CHDs) including hypoplastic right heart syndrome [30], univentricular heart [31] and Ebstein's anomaly [32]. Interestingly, hypoplastic right heart syndrome was associated with $\mathrm{Cw}$ LV-RBR, while univentricular heart and Ebstein's anomaly were associated with $\mathrm{CCw}$ LV-RBR in some individual patients. Abnormalities in the development of myocardial architecture during morphogenesis could be theorised to be responsible for LVRBR in these diseases [30-32].

Tetralogy of Fallot (TOF) is a cardiac anomaly with combination of ventricular septal defect, overriding aorta, pulmonary stenosis and right ventricular hypertrophy [3335]. In patients with corrected TOF from the MAGYARPath Study, 27\% of subjects showed Cw LV-RBR, while $11 \%$ of patients had CCw LV-RBR [33]. In case of corrected TOF patients with early total reconstruction, the same values proved to be beneficial compared to those who had early palliation and late correction. In another earlier study, the values of the same parameters were $15 \%$ and $18 \%$, respectively, with patients with almost zero LV rotations [34] (Fig. 4). In the study of Dragulescu et al. [35], $38 \%$ of corrected TOF patients showed CCw LV-RBR.

\section{Disorders with LV-RBR without obvious cardiac involvement}

\subsection{Acromegaly}

Acromegaly is a rare and chronic hormonal disorder that develops due to the hypersecretion of the human growth hormone $(\mathrm{GH})$ and insulin-like growth factor-1 (IGF-1) in adults [36-38]. LV-RBR could be detected in $20 \%$ of the cases with normal LV-EF (without obvious signs of classic acromegalic cardiomyopathy), which did not depend on the presence or absence of diabetes mellitus [37,38]. LVRBR proved to be $\mathrm{CCw}$ in $75 \%$ of cases, these abnormalities could be theorized to long-term effects of GH and IGF1 . 

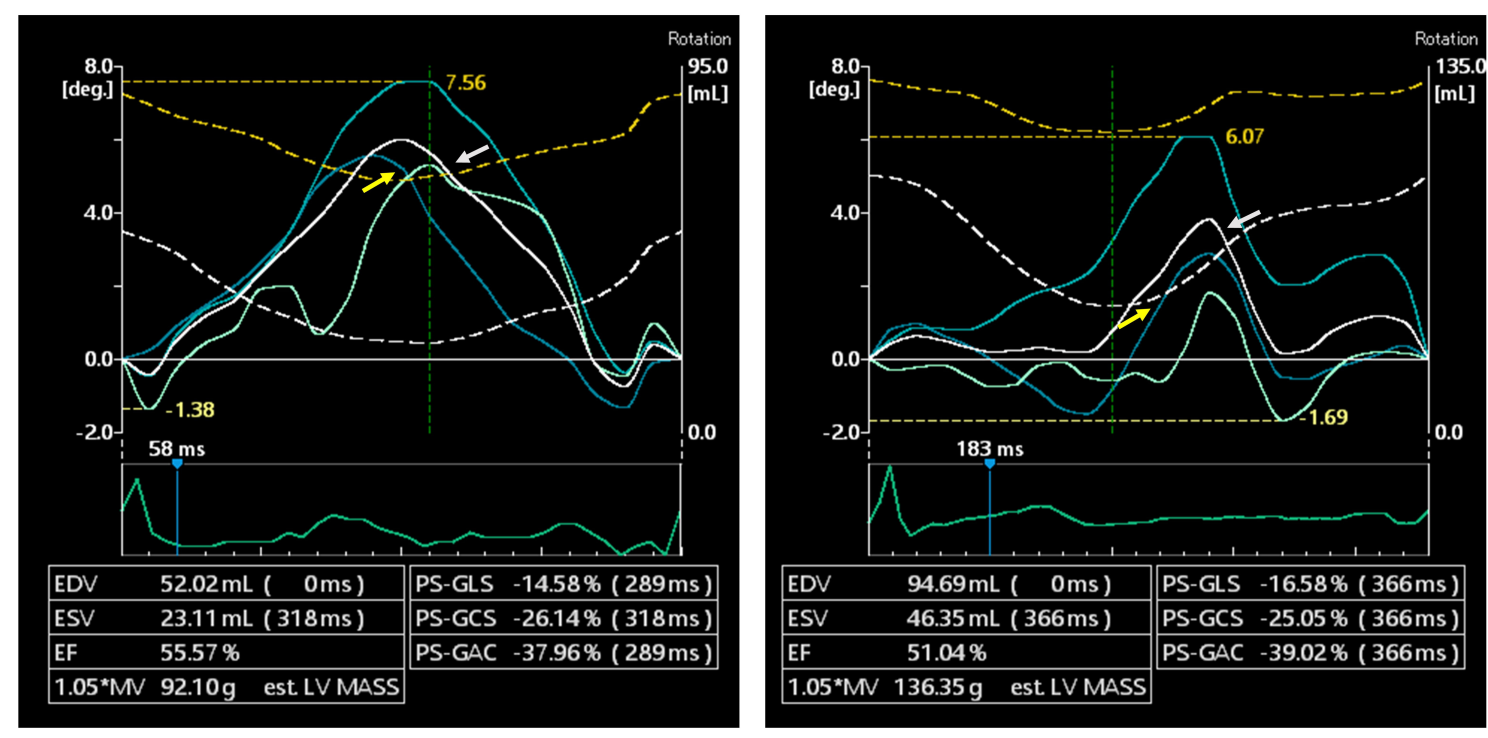

Fig. 3. Normal counterclockwise apical (white arrow) and abnormal counterclockwise basal (yellow arrow) left ventricular rotations (counterclockwise left ventricular 'rigid body rotation'). LV, left ventricular; EDV, end-diastolic volume; ESV, end-systolic volume; EF, ejection fraction; LV-GLS, LV global longitudinal strain; LV-GCS, LV global circumferential strain; LV-GAC, LV global area strain (change).

\subsection{Hypopituitarism}

Hypopituitarism is a rare and complex hormonal disease caused by the decreased secretion of one or more hormones in the pituitary gland. LV-RBR was present in 13\% of patients, potentially due to abnormal secretion of certain hormones [39].

\subsection{Lipedema and lymphedema}

While lipedema is a feminine disorder with disproportional, bilateral and symmetrical obesity of unknown pathomechanism, excessive accumulation of lymphatic fluid could be detected due to certain factors in lymphedema [40]. In several cases, lipedema and lymphedema are difficult to be differentiated clinically. However, in both disorders, the ratio of LV-RBR was similar (14\%) with typical $\mathrm{CCw}$ direction in lymphedema patients [40]. The use of compression medical stockings had significant effects on LV rotational mechanics both in lipedema [41] and lymphedema [42].

\subsection{Hidradenitis suppurativa}

Hidradenitis suppurativa is a dermatological disorder where chronic inflammation was suggested to be having effects on LV rotational mechanics [43].

\subsection{Haemophilia}

Haemophilia is an X-linked congenital coagulation factor deficiency. Although significant LV rotational abnormalities are present in haemophilia with reduced LV apical rotation and twist, ratio of patients with LV-RBR is not higher than in the normal population [44].

\subsection{Hypereosinophilic syndrome}

In hypereosinophilic syndrome (HES), peripheral eosinophilia and eosinophilic tissue/end-organ damage could be demonstrated [45]. In HES patients in the early necrotic stage, LV rotational abnormalities including presence of LV-RBR was found in $13 \%$ of cases.

\subsection{Following kidney transplantation}

In all patients with end-stage renal disease, kidney transplantation is the preferred treatment [46]. In posttransplant patients, ratio of LV-RBR was not significantly higher than in normal controls with $\mathrm{CCw}$ direction.

\subsection{Twin-to-twin transfusion syndrome}

In a recent case report, twin-to-twin transfusion syndrome was confirmed in the past medical history of an identical pair of twins who showed different patterns of LVRBR, Cw LV-RBR was described in the recipient twin and CCw LV-RBR was found in the donor twin [47]. Similarly to CHDs, abnormalities in the development of myocardial architecture could lead to LV-RBR in twin-to-twin transfusion syndrome theoretically.

\section{Healthy subjects and elite athletes}

In a current study demonstrating normal reference values of 3DSTE-derived LV rotational parameters and their age- and gender-dependency, $6 \%$ of cases proved to have LV-RBR. At the time of 3DSTE, these subjects had no abnormality, pathologic state, drug use, symptoms, electrocardiographic or echocardiographic findings, which could explain LV-RBR. Theoretically, these subjects had subclin- 
Table 1. Studies confirming left ventricular 'rigid body rotation' in different cardiac disorders.

\begin{tabular}{|c|c|c|c|c|}
\hline & Publication & Method & $\begin{array}{l}\text { No. of cases and ratio of } \\
\text { cases showing LV-RBR }\end{array}$ & $\begin{array}{l}\mathrm{Cw} / \mathrm{CCw} \\
\mathrm{LV}-\mathrm{RBR}\end{array}$ \\
\hline \multicolumn{5}{|c|}{ Cardiomyopathies } \\
\hline \multirow[t]{11}{*}{ - Noncompaction CM } & van Dalen et al. [11] & 2D-STE & $10(100 \%)$ & $\begin{array}{c}\mathrm{Cw}-70 \% \\
\mathrm{CCw}-30 \%\end{array}$ \\
\hline & van Dalen et al. [12] & 2D-STE & $34(88 \%)$ & $\begin{array}{c}\mathrm{Cw}-38 \% \\
\text { initial } \mathrm{CCw} \text {, then } \mathrm{Cw}-41 \% \\
\mathrm{CCw}-6 \% \\
\text { initial } \mathrm{Cw} \text {, then } \mathrm{CCw}-3 \%\end{array}$ \\
\hline & *Nemes et al. [13] & 3D-STE & 1 (case report) & $\mathrm{Cw}$ \\
\hline & *Kalapos et al. [14] & 3D-STE & $7(100 \%)$ & $\begin{array}{c}\mathrm{Cw}-29 \% \\
\mathrm{CCw}-71 \%\end{array}$ \\
\hline & Peters et al. [15] & 2D-STE & $60(53 \%)$ & $\begin{array}{c}\mathrm{Cw}-72 \% \\
\mathrm{CCw}-28 \%\end{array}$ \\
\hline & Cortés et al. [16] & 2D-STE & $28(57 \%)$ & - \\
\hline & Szücs et al. [17] & FT-MRI & $\begin{array}{l}\text { with LVEF < } 50 \% \\
\quad 31(42 \%) \\
\text { with LVEF > } 50 \% \\
\quad 31(26 \%)\end{array}$ & $\begin{array}{r}\mathrm{Cw}-92 \% \\
\mathrm{CCw}-8 \% \\
\mathrm{Cw}-12 \% \\
\mathrm{CCw}-88 \% \\
\end{array}$ \\
\hline & Akhan et al. [18] & 2DSTE & $\begin{array}{l}\text { NCCM patients } \\
32(53 \%) \\
\text { patients' relatives } \\
31(30 \%)\end{array}$ & $\begin{array}{c}\mathrm{Cw}-59 \% \\
\mathrm{CCw}-41 \% \\
\mathrm{Cw}-56 \% \\
\mathrm{CCw}-44 \% \\
\end{array}$ \\
\hline & Sabatino et al. [19] & 2DSTE & $\begin{array}{c}\text { NCCM children } \\
23(56 \%) \\
\text { hyper-trabecularization } \\
24(4 \%)\end{array}$ & $\mathrm{Cw}-100 \%$ \\
\hline & Nawaytou et al. [20] & 2DSTE & $\begin{array}{l}\text { NCCM children } \\
28(39 \%)\end{array}$ & $\begin{array}{l}\text { reverse apical rotation }(\mathrm{Cw}) \\
-100 \%\end{array}$ \\
\hline & Ashwal et al. [21] & 2DSTE & $12(50 \%)$ & $\mathrm{CCw}-100 \%$ \\
\hline $\begin{array}{l}\text { - Peripartum CM with noncom- } \\
\text { paction phenotype }\end{array}$ & Peters et al. [26] & 2D-STE & 1 (case report) & $\mathrm{CCw}$ \\
\hline - Hypertrophic CM & Ashwal et al. [21] & 2DSTE & $18(6 \%)$ & $\mathrm{Cw}$ \\
\hline - Chloroquine-induced CM & *Nemes et al. [27] & 3D-STE & 1 (case report) & $\mathrm{CCw}$ \\
\hline \multirow[t]{3}{*}{ - Dilated CM with reduced EF } & Popescu et al. [22] & 2D-STE & $50(52 \%)$ & $\mathrm{Cw}-100 \%$ \\
\hline & Cortés et al. [16] & 2D-STE & $13(15 \%)$ & - \\
\hline & Setser et al. [23] & MRI-TT & $21(76 \%)$ & $\begin{array}{c}\mathrm{Cw}-88 \% \\
\mathrm{CCw}-12 \% \\
\end{array}$ \\
\hline - Non-ischaemic CM & Taylor et al. [24] & FT-CMR & $\begin{array}{c}\text { with MWF } \\
32(64 \%) \\
\text { without MWF } \\
84(28 \%)\end{array}$ & - \\
\hline \multirow[t]{2}{*}{$\begin{array}{l}\text { - Hypertensive CM with re- } \\
\text { duced EF }\end{array}$} & Maharaj et al. [25] & 2D-STE & $41(32 \%)$ & $\mathrm{Cw}-85 \%$ \\
\hline & & & & $\mathrm{CCw}-15 \%$ \\
\hline
\end{tabular}


Table 1. Continued.

\begin{tabular}{|c|c|c|c|c|}
\hline & Publication & Method & $\begin{array}{l}\text { No. of cases and ratio of } \\
\text { cases showing LV-RBR }\end{array}$ & $\begin{array}{l}\mathrm{Cw} / \mathrm{CCw} \\
\mathrm{LV}-\mathrm{RBR}\end{array}$ \\
\hline \multicolumn{5}{|c|}{ Infiltrative disorders with cardiac involvement } \\
\hline - Cardiac lymphoma & *Nemes et al. [28] & 3D-STE & 1 (case report) & $\mathrm{CCw}$ \\
\hline - Cardiac amyloidosis & *Nemes et al. [29] & 3D-STE & $10(60 \%)$ & $\mathrm{CCw}-100 \%$ \\
\hline \multicolumn{5}{|c|}{ Congenital heart diseases } \\
\hline $\begin{array}{l}\text { - Hypoplastic right heart syn- } \\
\text { drome }\end{array}$ & *Nemes et al. [30] & 3D-STE & 1 (case report) & $\mathrm{Cw}$ \\
\hline - Univentricular heart & *Nemes et al. [31] & 3D-STE & 1 (case report) & $\mathrm{CCw}$ \\
\hline - Ebstein' anomaly & *Nemes et al. [32] & 3D-STE & 1 (case report) & $\mathrm{CCw}$ \\
\hline \multirow[t]{3}{*}{ - Tetralogy of Fallot } & *Nemes et al. [33] & 3D-STE & $26(38 \%)$ & $\begin{array}{c}\mathrm{Cw}-70 \% \\
\mathrm{CCw}-30 \%\end{array}$ \\
\hline & Menting et al. [34] & 2D-STE & $82(34 \%)$ & $\begin{array}{c}\mathrm{Cw}-46 \% \\
\mathrm{CCw}-54 \%\end{array}$ \\
\hline & Dragulescu et al. [35] & 2D-STE & $50(38 \%)$ & $\mathrm{CCw}-100 \%$ \\
\hline
\end{tabular}

2D, two-dimensional; 3D, three-dimensional; $\mathrm{Cw}$, clockwise; $\mathrm{CCw}$, counterclockwise; LV-RBR, left ventricular 'rigid body rotation'; CM, cardiomyopathy; LVEF, left ventricular ejection fraction; MWF, mid-wall fibrosis; NCCM, noncompaction cardiomyopathy; STE, speckle-tracking echocardiography; FT-CMR, feature-tracking cardiovascular magnetic resonance.

* Results from the MAGYAR-Path Study.

ical abnormalities or undiagnosed disorders which were not known at the time of 3DSTE [48]. In a study comparing $\mathrm{LV}$ rotational mechanics in NCCM patients and controls, $23 \%$ of healthy subjects showed CCw LV-RBR which higher rate could be partially explained by selection bias [17]. In contrast, none of the elite athletes doing high dynamic sports showed 3DSTE-proven LV-RBR in a recent study [49]. The above mentioned results suggest further examinations mainly focusing any diagnostic or prognostic impact of LV-RBR in subjects without symptoms or apparent abnormalities.

\section{Special considerations regarding LV-RBR}

\subsection{Clockwise vs. counterclockwise LV-RBR}

Normally, the LV base rotates clockwise, while the LV apex rotates in counterclockwise direction. In Cw LV-RBR, apical rotation of the $\mathrm{LV}$ has a clockwise direction (negative value on 3DSTE images, Fig. 2), while in CCw LV-RBR, basal rotation of the LV has a counterclockwise direction (positive value on 3DSTE images, Fig. 3). Direction of LV-RBR and their ratio in certain cardiac and non-cardiac disorders are presented in Tables 1 and 2 (Ref. [17,3640,43-49]). Interestingly, while most cardiomyopathy patients showed Cw LV-RBR [11,12,15,18,19,22,23,25], patients with non-cardiac disorders without obvious cardiac involvement (lymphedema, acromegaly, following kidney transplantation) most likely had CCw LV-RBR [37,40,46].

\subsection{Heart failure treatment, reversibility and $L V-R B R$}

A recent report described a patient with evidence of reversible LV-RBR who met the clinical criteria for the diagnosis of both peripartum cardiomyopathy and LV noncompaction with reduced LV-EF. Following 6-months heart failure treatment, improvement in LV-EF could be observed together with normalization of LV rotational mechanics [26].

\subsection{Vasodilation, stress test and LV-RBR}

Vasodilation and stress-related LV-RBR is weakly assessed. In a patient with previous coronary stenting presented with stable angina and positive exercise treadmill test, LV-RBR could be demonstrated, its characteristics changed dramatically during dipyridamole-induced vasodilatation [50]. A case of abnormal $\mathrm{CCw}$ rotation of the $\mathrm{LV}$ base was reported in a patient with angina pectoris without significant coronary artery disease (CAD) at rest, the direction of the rotation of the LV base changed to $\mathrm{CW}$ theoretically due to dipyridamole-induced vasodilation via improved blood supply at maximum hyperaemia [51]. At the recovery phase, LV-RBR could be detected again in this case. On the contrary, a CAD patient showed LV-RBR during dipyridamole stress, which normalized by the end of stress [52].

\section{4 'Clear' LV-RBR vs. LV-RBR with apico-basal gradient}

LV-RBR is the near absence of LV twist, when rotation at both apical and basal levels of the LV occur in the same $\mathrm{Cw}$ or $\mathrm{CCw}$ direction (Figs. 2,3,4). Although all segments move in the same direction, the amplitude of their motion 

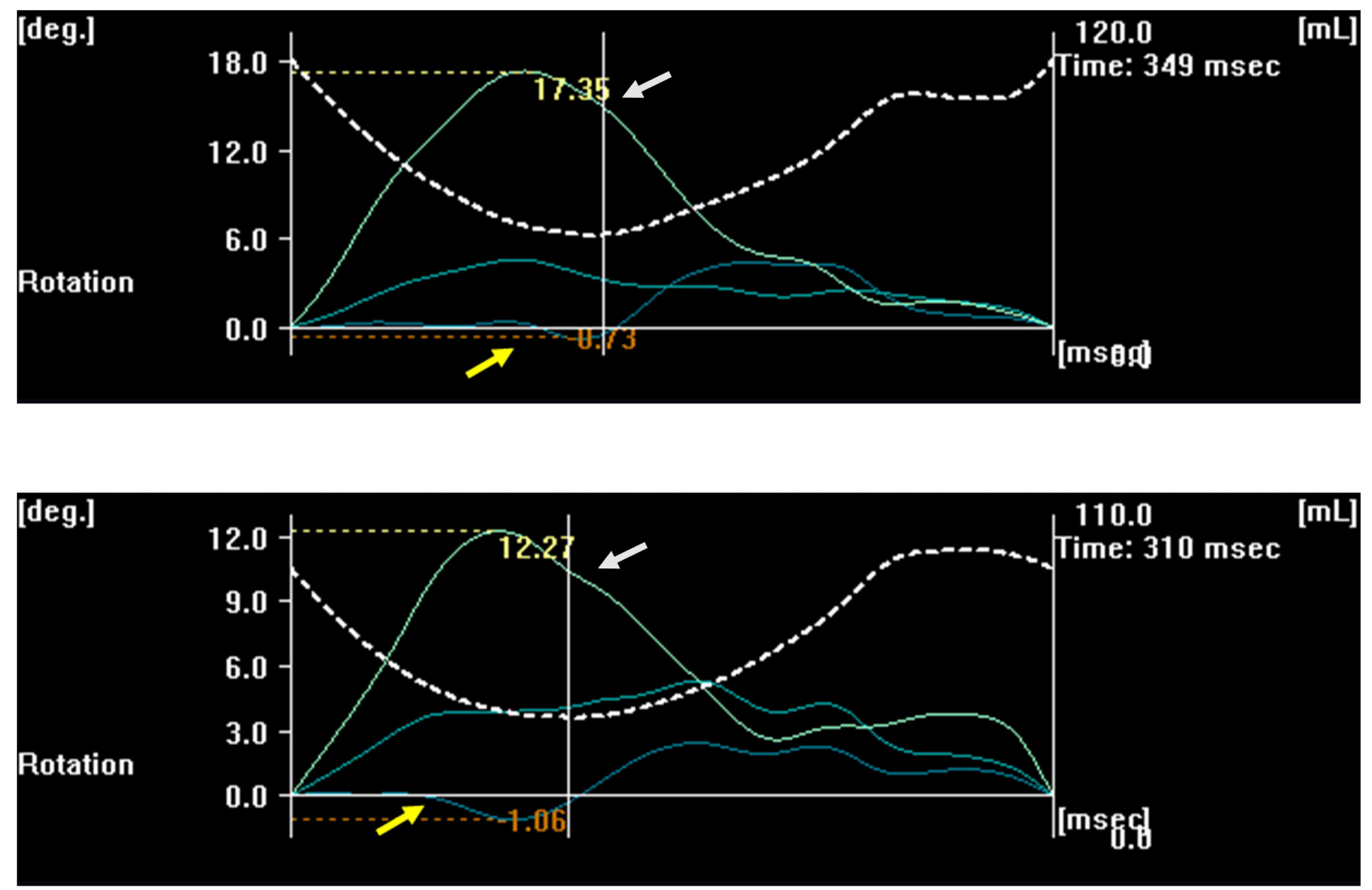

Fig. 4. Increased counterclockwise left ventricular apical rotation (white arrow) with almost zero left ventricular basal rotation (yellow arrow).
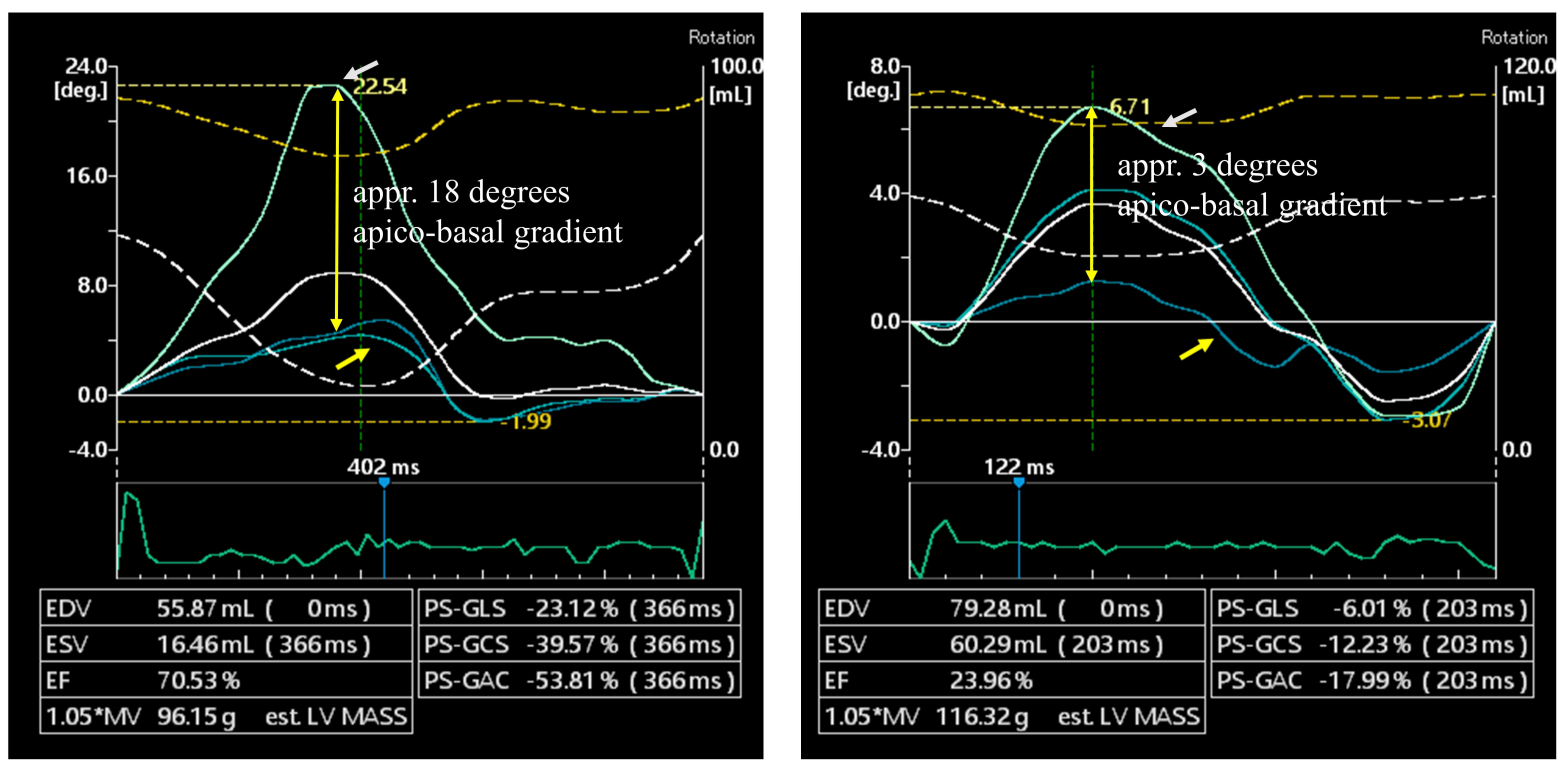

Fig. 5. Differences between apical and basal left ventricular rotations in the same counterclockwise direction demonstrating high (left panel) or low (right panel) left ventricular apico-basal rotational gradient. LV, left ventricular; EDV, end-diastolic volume; ESV, end-systolic volume; EF, ejection fraction; LV-GLS, LV global longitudinal strain; LV-GCS, LV global circumferential strain; LV-GAS, LV global area strain. 
Table 2. Studies confirming left ventricular 'rigid body rotation' in different non-cardiac diseases without known cardiac involvement.

\begin{tabular}{|c|c|c|c|c|}
\hline & Publication & Method & $\begin{array}{l}\text { No. of cases and ratio of } \\
\text { cases showing LV-RBR }\end{array}$ & $\begin{array}{l}\mathrm{Cw} / \mathrm{CCw} \\
\mathrm{LV}-\mathrm{RBR}\end{array}$ \\
\hline \multicolumn{5}{|c|}{ Healthy subjects } \\
\hline \multirow[t]{2}{*}{ - Healthy subjects } & *Kormányos et al. [48] & 3D-STE & $177(6 \%)$ & - \\
\hline & Szücs et al. [17] & FT-MRI & $31(23 \%)$ & $\mathrm{CCw}-100 \%$ \\
\hline $\begin{array}{l}\text { - Sportsmen doing high dy- } \\
\text { namic sports }\end{array}$ & *Gyenes et al. [49] & 3D-STE & $80(0 \%)$ & - \\
\hline \multicolumn{5}{|c|}{ Endocrine disorders } \\
\hline \multirow[t]{3}{*}{ - Acromegaly } & * Nemes et al. [36] & 3D-STE & 1 (case report) & $\mathrm{Cw}$ \\
\hline & *Kormányos et al. [37] & 3D-STE & $20(20 \%)$ & $\begin{array}{c}\mathrm{Cw}-25 \% \\
\mathrm{CCw}-75 \%\end{array}$ \\
\hline & *Nemes et al. [38] & 3D-STE & $\begin{array}{c}\text { with DM } \\
5(20 \%) \\
\text { without DM } \\
19(21 \%)\end{array}$ & - \\
\hline - Hypopituitarism & *Kormányos et al. [39] & 3D-STE & $31(13 \%)$ & $\begin{array}{c}\mathrm{Cw}-50 \% \\
\mathrm{CCw}-50 \%\end{array}$ \\
\hline \multicolumn{5}{|c|}{ Dermatological disorders } \\
\hline - Lipedema & *Nemes et al. [40] & 3D-STE & $22(14 \%)$ & $\begin{array}{c}\mathrm{Cw}-33 \% \\
\mathrm{CCw}-33 \% \\
\text { reversed twist } \\
-33 \%\end{array}$ \\
\hline - Lymphedema & *Nemes et al. [40] & 3D-STE & $22(14 \%)$ & $\mathrm{CCw}-100 \%$ \\
\hline - Hidradenitis suppurativa & *Nemes et al. [43] & 3D-STE & 1 (case report) & $\mathrm{CCw}$ \\
\hline \multicolumn{5}{|c|}{ Haematological disorders } \\
\hline - Haemophilia & *Nemes et al. [44] & 3D-STE & $14(7 \%)$ & $\mathrm{CCw}$ \\
\hline - Hypereosinophilic syndrome & *Nemes et al. [45] & 3D-STE & $11(18 \%)$ & $\begin{array}{c}\mathrm{Cw}-50 \% \\
\mathrm{CCw}-50 \%\end{array}$ \\
\hline \multicolumn{5}{|c|}{ Other diseases } \\
\hline $\begin{array}{l}\text { - Following kidney transplanta- } \\
\text { tion }\end{array}$ & *Nemes et al. [46] & 3D-STE & $38(8 \%)$ & $\mathrm{CCw}-100 \%$ \\
\hline $\begin{array}{l}\text { - Twin-to-twin transfusion syn- } \\
\text { drome }\end{array}$ & *Nemes et al. [47] & 3D-STE & 2 (case report) & $\begin{array}{l}\text { twin } \mathrm{A}-\mathrm{Cw} \\
\text { twin } \mathrm{B}-\mathrm{CCw}\end{array}$ \\
\hline
\end{tabular}

could be different leading to regional differences between apical and basal LV rotations called as LV apico-basal gradient (Fig. 5). In some disorders, LV apico-basal gradient could be elevated like in case of CA [29]. Its clinical significance is not known but could be considered as an overcompensation due to absence of normally directed LV rotational mechanics. Similar changes could be detected during stress as well [50-52].

\section{Prognostic value of $L V$-RBR}

Limited information is available regarding prognostic impact of LV-RBR. In a recent study, reverse LV apical rotation (Cw LV-RBR) was not a sensitive but a specific indicator of complications in children with NCCM suggesting its prognostic rather than diagnostic value [20]. 


\section{Possible pathophysiological explanations of LV-RBR}

Theoretically, changes in LV rotational mechanics may occur due to the above mentioned special factors, as well as due to classic risk factors, such as hypertension, hypercholesterolaemia, diabetes mellitus, etc. or subclinical diseases (focal/local oedema, inflammation, fibrosis, etc.). The effect of CAD and related haemodynamic changes could not be excluded either.

\section{The role of three-dimensional speckle-tracking (strain) echocardiography in current cardiology practice}

Although 3DSTE is not a guideline-recommended technique at this moment, it has several advantages as compared to other echocardiographic methods. It sees the heart as it is: a $3 \mathrm{D}$ organ and all volumetric, functional (strain) and rotational parameters of heart chambers respecting the cardiac cycle can be calculated at the same time using the same virtual 3D models based on digitally acquired echocardiographic datasets. Moreover, data acquisition and analysis do not require significantly more time in practical hands than a routine echocardiographic examination. These facts could highlight its importance in clinical practice in more complicated cases, which require more detailed analysis (for instance in heart failure or following myocardial infarction). As demonstrated above, 3DSTE-derived parameters could help in differentiating NCCM from LV 'hypertrabecularization' or HCM from cardiac amyloidosis [12,53]. Moreover, prognostic impact of 3DSTE-derived ejection fraction and 3D strain parameters has also been demonstrated [54,55]. 3DSTE allows detailed assessment of the right ventricle and both atria, as well $[53,55]$. The role of 3DSTE in the assessment of atrioventricular valvular annuli has also been demonstrated [56].

Most of echocardiographic laboratories have access to 2D strain software and LV rotational parameters can be calculated with them, 3DSTE-derived ones are recommended according to the guidelines [5]. Although 2DSTE-derived global longitudinal strain is well known and a widely used parameter with a strong progmostic impact [57], limitations of 2DSTE should always be considered, when LV rotations are calculated.

\section{Conclusions}

LV-RBR is defined as the near absence of LV twist when LV apical and basal segments move in the same clockwise or counterclockwise direction. LV-RBR could be demonstrated in a number of diseases with larger prevalence in certain disorders with cardiac involvement. However, some non-cardiac diseases without overt cardiovascular involvement show limited prevalence of LV-RBR without obvious significance, which would require further investigations.

\section{Author contributions}

$\mathrm{AN}$ and ÁK designed the research study, performed the research and analyzed the data. All authors contributed to editorial changes in the manuscript. All authors read and approved the final manuscript.

\section{Ethics approval and consent to participate}

All subjects gave their informed consent for inclusion before they participated in the MAGYAR studies. The study was conducted in accordance with the Declaration of Helsinki, and the protocol was approved by the Ethics Committee of University of Szeged (approval number: 71/2011).

\section{Acknowledgment}

We would like to express our gratitude to all those who helped us during the writing of this manuscript. Thanks to all the peer reviewers for their opinions and suggestions.

\section{Funding}

This research received no external funding.

\section{Conflict of interest}

The authors declare no conflict of interest. Attila Nemes is serving as one of the Editorial Board members of this journal. We declare that Attila Nemes had no involvement in the peer review of this article and has no access to information regarding its peer review. Full responsibility for the editorial process for this article was delegated to Tasneem Z. Naqvi.

\section{References}

[1] Nakatani S. Left ventricular rotation and twist: why should we learn? Journal of Cardiovascular Ultrasound. 2011; 19: 1-6.

[2] Sallin EA. Fiber orientation and ejection fraction in the human left ventricle. Biophysical Journal. 1969; 9: 954-964.

[3] Geerts L, Bovendeerd P, Nicolay K, Arts T. Characterization of the normal cardiac myofiber field in goat measured with MRdiffusion tensor imaging. American Journal of Physiology-Heart and Circulatory Physiology. 2002; 283: H139-H145.

[4] Sedmera D, Pexieder T, Vuillemin M, Thompsin RP, Anderson RH. Developmental patterning of the myocardium. The Anatomical Record. 2000; 258: 319-337.

[5] Voigt JU, Pedrizzetti G, Lysyansky P, Marwick TH, Houle $\mathrm{H}$, Baumann R, et al. Definitions for a common standard for 2D speckle tracking echocardiography: consensus document of the EACVI/ASE/Industry Task Force to standardize deformation imaging. European Heart Journal Cardiovascular Imaging. 2015; 16: 1-11.

[6] Andrade J, Cortez LD, Campos O, Arruda AL, Pinheiro J, Vulcanis L, et al. Left ventricular twist: comparison between two- and three-dimensional speckle-tracking echocardiography in healthy volunteers. European Journal of Echocardiography. 2011; 12: 76-79.

[7] Nemes A, Kalapos A, Domsik P, Forster T. Three-dimensional speckle-tracking echocardiography - a further step in noninvasive three-dimensional cardiac imaging. Orvosi Hetilap. 2012; 153: 1570-1577. (In Hu) 
[8] Nemes A, Kalapos A, Domsik P, Forster T. Left ventricular rotation and twist of the heart. Clarification of some concepts. Orvosi Hetilap. 2012; 153: 1547-1551. (In Hu)

[9] Notomi Y, Srinath G, Shiota T, Martin-Miklovic MG, Beachler $\mathrm{L}$, Howell K, et al. Maturational and Adaptive Modulation of Left Ventricular Torsional Biomechanics: Doppler tissue imaging observation from infancy to adulthood. Circulation. 2006; 113: 2534-2541.

[10] Jenni R, Oechslin E, Schneider J, Attenhofer Jost C, Kaufmann PA. Echocardiographic and pathoanatomical characteristics of isolated left ventricular non-compaction: a step towards classification as a distinct cardiomyopathy. Heart. 2001; 86: 666-671.

[11] van Dalen BM, Caliskan K, Soliman OI, Nemes A, Vletter WB, Ten Cate FJ, et al. Left ventricular solid body rotation in non-compaction cardiomyopathy: a potential new objective and quantitative functional diagnostic criterion? European Journal of Heart Failure. 2008; 10: 1088-1093.

[12] van Dalen BM, Caliskan K, Soliman OII, Kauer F, van der Zwaan HB, Vletter WB, et al. Diagnostic Value of Rigid Body Rotation in Noncompaction Cardiomyopathy. Journal of the American Society of Echocardiography. 2011; 24: 548-555.

[13] Nemes A, Kalapos A, Domsik P, Forster T. Identification of Left Ventricular "Rigid Body Rotation" by Three-Dimensional Speckle-Tracking Echocardiography in a Patient with Noncompaction of the Left Ventricle: a Case from the MAGYAR-Path Study. Echocardiography. 2012; 29: E237-E240.

[14] Kalapos A, Domsik P, Forster T, Nemes A. Comparative evaluation of left ventricular function by two-dimensional echocardiography and three-dimensional speckle-tracking echocardiography in noncompaction cardiomyopathy. Results from the MAGYAR-Path Study. Orvosi Hetilap. 2013; 154: 1352-1359. (In $\mathrm{Hu})$

[15] Peters F, Khandheria BK, Libhaber E, Maharaj N, dos Santos C, Matioda $\mathrm{H}$, et al. Left ventricular twist in left ventricular noncompaction. European Heart Journal - Cardiovascular Imaging. 2014; 15: 48-55.

[16] Cortés M, Oliva MR, Orejas M, Navas MA, Rábago RM, Martínez ME, et al. Usefulness of speckle myocardial imaging modalities for differential diagnosis of left ventricular noncompaction of the myocardium. International Journal of Cardiology. 2016; 223: 813-818.

[17] Szücs A, Kiss AR, Gregor Z, Horváth M, Tóth A, Dohy Z, et al. Changes in strain parameters at different deterioration levels of left ventricular function: a cardiac magnetic resonance featuretracking study of patients with left ventricular noncompaction. International Journal of Cardiology. 2021; 331: 124-130.

[18] Akhan O, Demir E, Dogdus M, Cakan FO, Nalbantgil S. Speckle tracking echocardiography and left ventricular twist mechanics: predictive capabilities for noncompaction cardiomyopathy in the first degree relatives. The International Journal of Cardiovascular Imaging. 2021; 37: 429-438.

[19] Sabatino J, Di Salvo G, Krupickova S, Fraisse A, Prota C, Bucciarelli V, et al. Left Ventricular Twist Mechanics to Identify Left Ventricular Noncompaction in Childhood. Circulation. Cardiovascular imaging. 2019; 12: e007805.

[20] Nawaytou HM, Montero AE, Yubbu P, Calderón-Anyosa RJC, Sato T, O'Connor MJ, et al. A Preliminary Study of Left Ventricular Rotational Mechanics in Children with Noncompaction Cardiomyopathy: Do They Influence Ventricular Function? Journal of the American Society of Echocardiography. 2018; 31: 951-961.

[21] Ashwal AJ, Mugula SR, Samanth J, Paramasivam G, Nayak K, Padmakumar R. Role of deformation imaging in left ventricular non-compaction and hypertrophic cardiomyopathy: an Indian perspective. The Egyptian Heart Journal. 2020; 72: 6.

[22] Popescu BA, Beladan CC, Călin A, Muraru D, Deleanu D, Roşca
$\mathrm{M}$, et al. Left ventricular remodelling and torsional dynamics in dilated cardiomyopathy: reversed apical rotation as a marker of disease severity. European Journal of Heart Failure. 2009; 11: 945-951.

[23] Setser RM, Kasper JM, Lieber ML, Starling RC, McCarthy PM, White RD. Persistent abnormal left ventricular systolic torsion in dilated cardiomyopathy after partial left ventriculectomy. The Journal of Thoracic and Cardiovascular Surgery. 2003; 126: 4855.

[24] Taylor RJ, Umar F, Lin ELS, Ahmed A, Moody WE, Mazur W, et $a l$. Mechanical effects of left ventricular midwall fibrosis in nonischemic cardiomyopathy. Journal of Cardiovascular Magnetic Resonance. 2016; 18: 1.

[25] Maharaj N, Khandheria BK, Peters F, Libhaber E, Essop MR. Time to twist: marker of systolic dysfunction in Africans with hypertension. European Heart Journal - Cardiovascular Imaging. 2013; 14: 358-365.

[26] Peters F, Khandheria BK, dos Santos C, Govender S, Botha F, Essop MR. Peripartum Cardiomyopathy Associated with Left Ventricular Noncompaction Phenotype and Reversible Rigid Body Rotation. Circulation: Heart Failure. 2013; 6: e62-e63.

[27] Nemes A, Nagy V, Domsik P, Kalapos A, Kormányos Á, Havasi K, Forster T. Left ventricular rotational abnormalities in chloroquine-induced cardiomyopathy (from the MAGYAR-Path Study). Minerva Cardioangiol. 2018; 66: 786-787.

[28] Földeák D, Kalapos A, Domsik P, Sinkó M, Szeleczki N, Bagdi E, et al. Left ventricular rigid body rotation in a diffuse large B-cell lymphoma patient with cardiac involvement: A case from the three-dimensional speckle-tracking echocardiographic MAGYAR-Path Study. Revista Portuguesa de Cardiologia. 2017; 36: 145.e1-145.e5.

[29] Nemes A, Földeák D, Domsik P, Kalapos A, Sepp R, Borbényi Z, et al. Different patterns of left ventricular rotational mechanics in cardiac amyloidosis-results from the three-dimensional speckletracking echocardiographic MAGYAR-Path Study. Quantitative Imaging in Medicine and Surgery. 2015; 5: 853-857.

[30] Nemes A, Havasi K, Forster T. "Rigid body rotation" of the left ventricle in hypoplastic right-heart syndrome: a case from the three-dimensional speckle-tracking echocardiographic MAGYAR-Path Study. Cardiology in the Young. 2015; 25: 768-772.

[31] Nemes A, Havasi K, Domsik P, Kalapos A, Forster T. Can univentricular heart be associated with "rigid body rotation"? A case from the three-dimensional speckle-tracking echocardiographic MAGYAR-Path Study. Hellenic Journal of Cardiology. 2015; 56: 186-188.

[32] Nemes A, Havasi K, Domsik P, Kalapos A, Forster T. Left Ventricular Rigid Body Rotation in Ebstein's Anomaly from the MAGYAR-Path Study. Arquivos Brasileiros de Cardiologia. 2016; 160: 544-545.

[33] Nemes A, Rácz G, Kormányos Á, Domsik P, Kalapos A, Gyenes $\mathrm{N}$, et al. Left ventricular rotational abnormalities in adult patients with corrected tetralogy of Fallot following different surgical procedures (Results from the CSONGRAD Registry and MAGYAR-Path Study). Cardiovascular Diagnosis and Therapy. 2021; 11: 623-630.

[34] Menting ME, Eindhoven JA, van den Bosch AE, Cuypers JAAE, Ruys TPE, van Dalen BM, et al. Abnormal left ventricular rotation and twist in adult patients with corrected tetralogy of Fallot. European Heart Journal - Cardiovascular Imaging. 2014; 15 : 566-574.

[35] Dragulescu A, Friedberg MK, Grosse-Wortmann L, Redington A, Mertens L. Effect of Chronic Right Ventricular Volume Overload on Ventricular Interaction in Patients after Tetralogy of Fallot Repair. Journal of the American Society of Echocardiography. 2014; 27: 896-902. 
[36] Nemes A, Kormányos Á, Domsik P, Kalapos A, Lengyel C, Valkusz Z, et al. Left ventricular 'rigid body rotation' in a patient with acromegaly (from the MAGYAR-Path Study). Quantitative Imaging in Medicine and Surgery. 2017; 7: 378-379.

[37] Kormányos Á, Domsik P, Kalapos A, Orosz A, Lengyel C, Valkusz Z, et al. Left ventricular twist is impaired in acromegaly: Insights from the three-dimensional speckle tracking echocardiographic MAGYAR-Path Study. Journal of Clinical Ultrasound. 2018; 46: 122-128.

[38] Nemes A, Kormányos Á, Domsik P, Kalapos A, Gyenes $\mathrm{N}$, Lengyel $\mathrm{C}$, et al. Diabetes mellitus deteriorates left ventricular deformation in acromegaly - analysis from the threedimensional speckle-tracking echocardiographic MAGYARPath Study. Quantitative Imaging in Medicine and Surgery. 2021; 11: 410-414

[39] Kormányos Á, Gyenes N, Horváth Á, Ambrus N, Lengyel C, Valkusz Z, et al. Left Ventricular Rotational Abnormalities in Treated Hypopituitarism: Insights From the ThreeDimensional Speckle-Tracking Echocardiographic MAGYARPath Study. Frontiers in Cardiovascular Medicine. 2021; 8: 703146.

[40] Nemes A, Kormányos A, Domsik P, Kalapos A, Keméeny L, Forster $\mathrm{T}$, et al. Left ventricular rotational mechanics differ between lipedema and lymphedema: Insights from the threedimensional speckle tracking echocardiographic MAGYARPath Study. Lymphology. 2018; 51: 102-108.

[41] Nemes A, Kormányos Á, Domsik P, Kalapos A, Kemény L, Szolnoky G. The impact of lower body compression garment on left ventricular rotational mechanics in patients with lipedemaInsights from the three-dimensional speckle tracking echocardiographic MAGYAR-Path Study. Clinical Obesity. 2020; 10: e12380.

[42] Nemes A, Kormányos Á, Domsik P, Kalapos A, Kemény L, Szolnoky G. The effects of lower body compression on left ventricular rotational mechanics in lymphoedema (from the MAGYAR-Path Study). ESC Heart Failure. 2021; 8: 4328-4333.

[43] Nemes A, Kovács R, Kormányos Á, Szolnoky G, Kalapos A, Domsik P, et al. Rigid body rotation of the left ventricle in hidradenitis suppurativa (a case from the three-dimensional speckle-tracking echocardiographic MAGYAR-Path Study). Quantitative Imaging in Medicine and Surgery. 2018; 8: 547550.

[44] Nemes A, Kormányos Á, Domsik P, Ambrus N, Gyenes N, Vezendi $\mathrm{K}$, et al. Left ventricular rotational abnormalities in hemophilia-Insights from the three-dimensional speckletracking echocardiographic MAGYAR-Path Study. Quantitative Imaging in Medicine and Surgery. 2022. (in press)

[45] Nemes A, Kormányos Á, Domsik P, Kalapos A, Ambrus $\mathrm{N}$, Modok $\mathrm{S}$, et al. Left ventricular rotational mechanics in hypereosinophilic syndrome-Analysis from the three-dimensional speckle-tracking echocardiographic MAGYAR-Path Study. Echocardiography. 2019; 36: 2064-2069.

[46] Borda B, Kormányos Á, Domsik P, Kalapos A, Lengyel C, Ambrus $\mathrm{N}$, et al. Left ventricular rotational abnormalities following successful kidney transplantation-insights from the threedimensional speckle-tracking echocardiographic MAGYARPath Study. Quantitative Imaging in Medicine and Surgery. 2018; 8: 1095-1101.
[47] Nemes A, Katona M, Domsik P, Kalapos A, Forster T. Different patterns of left ventricular 'rigid body rotation' in 8year-old twins with anamnaestic twin-to-twin transfusion syndrome (from the MAGYAR-Twin Study). Quantitative Imaging in Medicine and Surgery. 2017; 7: 140-141.

[48] Kormányos Á, Kalapos A, Domsik P, Lengyel C, Forster T, Nemes A. Normal values of left ventricular rotational parameters in healthy adults-Insights from the three-dimensional speckle tracking echocardiographic MAGYAR-Healthy Study. Echocardiography. 2019; 36: 714-721.

[49] Gyenes N, Kormányos Á, Vágvölgyi A, Domsik P, Kalapos A, Ambrus N, et al. Left ventricular rotational mechanics in elite athletes doing high dynamic sports. Insights from the 3D speckle-tracking echocardiographic MAGYAR-Sport Study. The Journal of Sports Medicine and Physical Fitness. 2021; 61: 1007-1012.

[50] Nemes A, Szántó G, Domsik P, Kormányos Á, Kalapos A, Ambrus N, et al. Change of left ventricular "rigid body rotation" during dipyridamole-induced vasodilation: a case from the threedimensional speckle tracking echocardiographic MAGYARStress Study. Journal of Clinical Ultrasound. 2018; 46: 152-156.

[51] Nemes A, Szántó G, Kalapos A, Domsik P, Forster T. Reversal of left ventricular "rigid body rotation" during dipyridamoleinduced stress in a patient with stable angina: a case from the three-dimensional speckle tracking echocardiographic MAGYAR-Stress Study. Quantitative Imaging in Medicine and Surgery. 2016; 6: 308-311.

[52] Nemes A, Szántó G, Kalapos A, Domsik P, Kormányos Á, Ambrus N, et al. Dipyridamole-induced Left ventricular "Rigid Body Rotation" (a case from the three-dimensional speckle tracking echocardiographic MAGYAR-stress study). Journal of Cardiovascular Echography. 2019; 29: 39-42.

[53] Földeák D, Kormányos Á, Domsik P, Kalapos A, Piros GÁ, Ambrus N, et al. Left atrial dysfunction in light-chain cardiac amyloidosis and hypertrophic cardiomyopathy - a comparative three-dimensional speckle-tracking echocardiographic analysis from the MAGYAR-Path Study. Revista Portuguesa de Cardiologia. 2017; 36: 905-913.

[54] Coutinho Cruz M, Moura Branco L, Portugal G, Galrinho A, Timóteo AT, Rio P, et al. Three-dimensional speckle-tracking echocardiography for the global and regional assessments of left ventricle myocardial deformation in breast cancer patients treated with anthracyclines. Clinical Research in Cardiology. 2020; 109: 673-684.

[55] Meng Y, Zhu S, Xie Y, Zhang Y, Qian M, Gao L, et al. Prognostic value of right ventricular 3D speckle-tracking strain and ejection fraction in patients with HFpEF. Frontiers in Cardiovascular Medicine. 2021; 8: 694365.

[56] Nemes A, Kovács Z, Kormányos Á, Domsik P, Kalapos A, Piros GÁ, et al. The mitral annulus in lipedema: Insights from the three-dimensional speckle-tracking echocardiographic MAGYAR-Path Study. Echocardiography. 2019; 36: 14821491.

[57] Abou R, Goedemans L, Montero-Cabezas JM, Prihadi EA, El Mahdiui M, Schalij MJ, et al. Prognostic Value of Multilayer Left Ventricular Global Longitudinal Strain in Patients with STsegment Elevation Myocardial Infarction with Mildly Reduced Left Ventricular Ejection Fractions. American Journal of Cardiology. 2021; 152: 11-18. 